\title{
Microencapsulation of Bovine Vaginal Lactobacilli in Alginate Using Emulsion-gelation: Freeze-drying, Storage and Antimicrobial Activity
}

Ale $\mathrm{CE}^{1}$, Torres Luque $\mathrm{A}^{1}$, Gonzalez Moreno $\mathrm{C}^{2}$ and Otero $\mathrm{MC}^{{ }^{*}}$

${ }^{1}$ Instituto Superior de Investigaciones Biológicas (INSIBIO), CONICET-UNT, and Instituto de Biología "Dr. Francisco D. Barbieri", Facultad de Bioquímica, Química y Farmacia, UNT, San Miguel de Tucumán, Argentina.

${ }^{2}$ Facultad de Agronomía y Zootecnia, Universidad Nacional de Tucumán. CONICET, Florentino Ameghuino S/N, Barrio Mercantil. EI Manantial. CP: 4105. TucumánArgentina

\begin{abstract}
Probiotics containing autochthonous Lactic Acid Bacteria (LAB) as local treatment in the Bovine Reproductive Tract (BRT) was proposed as a sustainable alternative to prevent outcome of pathogens colonization in the postpartum uterus in cows. Microencapsulation of these LABs could improve their survival during stressing conditions and promote the intimate contact between the veterinarian form and the vaginal mucosa. In this work, emulsion-ionic gelation technique was applied to encapsulate bovine $L A B$ strains in an alginate $(3 \%)$ matrix. Optical and scanning electron microscopic evaluations showed spheroidal particles $(12-48 \mu \mathrm{m})$ with a fully charge of $L A B$; the average load ranged $8.98 \pm 0.15$ to $8.06 \pm 0.21 \mathrm{log} C F U / \mathrm{g}$. The microencapsulated lactic acid bacteria (LAB-MCs) stability was evaluated during lyophilization [in Skim Milk (SM), or Neutral Distilled Water (NDW)] and storage (at $4^{\circ} \mathrm{C}$ up to 90 days). SM represented a significant high protection to the lyophilization. Also, the alginate microencapsulation improved the LAB strain resistance when freeze-dried in water, comparing to known sensibility of LAB free cells. L. gasseri CRL 1412 showed similar resistance in both, NDW $(0.70 \pm 0.05)$ and SM $(0.72 \pm 0.05)$; and their microcapsules (MCs) exhibited antagonistic activity against $E$. coli $99 / 14$ (pathogen from Bovine metritis) when cultured together; contrary, in co-culture with empty-MCs no inhibition was observed. To evaluate the microencapsulation process, different parameters were estimated: Encapsulation Factor (EF) (ranged between $0.76 \pm 0.03$ and $0.85 \pm 0.08$ ) and Encapsulating Efficiency (EE) (average EE\%=75\%) none significant differences (LSDFisher test, $P<0.05$ ) were observed between $L A B$ strains. Taking account the weight of the materials, the calculated average yield was $50.5 \%$. The standardized encapsulation conditions allowed selected L. gasseri CRL 1412-MCs as potential systems to be included in formulations to restore vaginal microbiota to prevent metritis in cows.
\end{abstract}

\section{Keywords: Bovine Lactobacillus; Emulsion-gelation microencapsulation; E. coli; Metritis}

\section{Introduction}

The infectious diseases in the Bovine Reproductive Tract (BRT) reduce the efficiency in herds by incurring substantial economic costs [1]. Moreover, they increase the calving to conception period, decrease the conception/insemination rate and affect milk production, resulting in the lack of new lactations and low food intake [2]. Antibiotic and hormonal therapies resolve acute infectious outbreaks but do not improve fertility [1]. These substances remain present in foodstuff as residues and could produce environmental problems associated with the spread of antibiotic resistance [3].

Probiotics containing Lactic Acid Bacteria (LAB) were proposed to control infectious diseases in the veterinary area [4-8]. Thus, the use of LAB as local treatment in the BRT to prevent the outcome of pathogens colonization in the postpartum uterus represents a sustainable alternative [9]. The Lactobacillus genus was described as able to colonize the bovine vagina of healthy heifers and cows $[10,11]$. Among the mechanisms involved in the beneficial effect of probiotics, the suppression of pathogenic or potentially pathogenic bacterial growth, competitive exclusion and the stimulation of the immune system can be pointed out $[7,12]$.

The probiotic effect depends on the amount of microorganisms administered, which is directly related to the method of obtainment and conservation. Low temperature of storage (freezing or refrigeration) and freeze-drying are common ways to stabilize probiotics. However, lyophilized cultures are favored over frozen ones according to transport and storage costs [13].

Microencapsulation is a technology for the packaging of solid, liquid and gaseous materials in small capsules that release their contents at controlled conditions during sustained time periods $[14,15]$.
The preservation of probiotics through microencapsulation into hydrocolloid beads prepared by extrusion and emulsion techniques or into spray-dried micro particles has been well studied [16]. The microencapsulation confers cells protection from environmental factors increasing its survival to freeze drying, freezing and storage and converting them into a powder form easier to incorporate in a veterinary formulation [17]. Thus, microencapsulation has been recognized as an effective way to enhance the LAB viability and has been also used in the food industry [18]. Alginate is one of the most widely used encapsulating materials, which is a linear heteropolysaccharide composed of $\beta$-D-mannuronic acid and $\alpha$-L-guluronic acid. Extrusion or emulsification techniques are usually used to obtain alginate beads [18]. This polymer possesses mucoadhesive properties and therefore was used for drugs release in human vagina [19].

The aim of this work was to evaluate the microencapsulation and freeze-drying conditions of vaginal Lactobacillus to go further in the formulation of veterinary products containing indigenous strains to be applied in the BRT.

*Corresponding author: María Claudia Otero, Instituto Superior de Investigaciones Biológicas (INSIBIO), CONICET-UNT, and Instituto de Biología "Dr. Francisco D. Barbieri", Facultad de Bioquímica, Química y Farmacia, UNT, San Miguel de Tucumán, Argentina, Tel: +54-381-424-7752 extn. 7093, 203; Fax: +54-381-4247752 extn. 7004; E-mail: oteromariaclaudia@gmail.com

Received November 10, 2015; Accepted November 20, 2015; Published Novembe 24, 2015

Citation: Ale CE, Torres Luque A, Gonzalez Moreno C, Otero MC (2015) Microencapsulation of Bovine Vaginal Lactobacilli in Alginate Using Emulsiongelation: Freeze-drying, Storage and Antimicrobial Activity. J Bioprocess Biotech 5 262. doi:10.4172/2155-9821.1000262

Copyright: ( 2015 Ale CE, et al. This is an open-access article distributed under the terms of the Creative Commons Attribution License, which permits unrestricted use, distribution, and reproduction in any medium, provided the original author and source are credited. 
Citation: Ale CE, Torres Luque A, Gonzalez Moreno C, Otero MC (2015) Microencapsulation of Bovine Vaginal Lactobacilli in Alginate Using Emulsion-gelation: Freeze-drying, Storage and Antimicrobial Activity. J Bioprocess Biotech 5: 262. doi:10.4172/2155-9821.1000262

Page 2 of 8

\section{Materials and Methods}

\section{Bacterial strains and culture conditions}

Lactobacillus gasseri CRL 1412, L. gasseri CRL 1421, L. gasseri CRL 1460 and L. delbrueckii subsp. delbrueckii CRL 1461 were isolated in previous studies $[10,11]$ from the posterior area of the vagina of healthy cows and selected for their beneficial properties $[9,20]$ to prevent bovine metritis. The LAB strains were grown in MRS broth (Merck, Darmstadt, Germany) [21], pH 6.5 and incubated for 12-14 $\mathrm{h}$ at $37^{\circ} \mathrm{C}$ in microaerophilic conditions (5\% $\mathrm{CO}_{2}$-enriched chamber). Escherichia coli $99 / 14$ isolated from clinical material of cows displaying metritis was grown in LAPTg broth [22], pH 6.8 for $6 \mathrm{~h}$ at $37^{\circ} \mathrm{C}$. All microorganisms were stored in milk-yeast extract (13\% skim milk, $1 \%$ yeast extract) at $-20^{\circ} \mathrm{C}$.

\section{Bacterial suspensions for microencapsulation}

LAB strains were subsequently propagated in 5, 70 and $700 \mathrm{ml}$ MRS broth, under the conditions cited above. The microorganisms were harvested at the early stationary phase of growth $(12 \mathrm{~h}$, reached approximately $10^{9} \mathrm{CFU} / \mathrm{ml}$ ). The pellet of each strain was washed two times with sterile saline solution and centrifuged at $3,000 \times \mathrm{g}$, for 10 $\min$ at $4^{\circ} \mathrm{C}$. Finally, 100-times concentrated bacterial suspensions were prepared.

\section{Encapsulating materials}

A 3\% (w/v) sodium alginate (from brown algae, middle viscosity) solution was prepared with deionized water, with stirring and heating at $80^{\circ} \mathrm{C}$. Solutions were sterilized $\left(121^{\circ} \mathrm{C}, 10 \mathrm{~min}\right)$ and stored at $4^{\circ} \mathrm{C}$ until used. Calcium chloride $(0.05 \mathrm{M})$, sodium chloride $(0.9 \% \mathrm{w} / \mathrm{v})$ and $\mathrm{KH}_{2} \mathrm{PO}_{4}-\mathrm{K}_{2} \mathrm{HPO}_{4}$ buffer, $\mathrm{pH} 6.8$ were also prepared. Ricinus communis vegetable oil and Tween 20 were used as oil phase and surfactant agent, respectively. All drugs were purchased from Cicarelli Laboratories (Argentina) with the exception of Tween 20 (Anedra Research AG) and sodium alginate (MP Biomedicals, Argentina).

\section{Microencapsulation of lactic acid bacteria strains}

Modifications to the microencapsulation method proposed by one study [21] were performed. Briefly, $7 \mathrm{ml}$-concentrated LAB suspensions (Bacterial suspensions for microencapsulation section) were mixed with $25 \mathrm{ml}$ sodium alginate (3\%) by stirring for $1 \mathrm{~min}$ at room temperature $\left(25 \pm 2^{\circ} \mathrm{C}\right)$. The bacteria-alginate mixtures were prepared as described for the emulsion method. Thus, mixtures were dispersed in $150 \mathrm{ml}$ oil phase and $250 \mu \mathrm{l}$ surfactant agent. After emulsification, $40 \mathrm{ml} 0.05 \mathrm{M} \mathrm{CaCl}_{2}$ were added and the mixture was vigorously stirred. Samples were allowed to stand for $30 \mathrm{~min}$ until oil and aqueous phase separations. The microcapsules (MCs) with LAB were harvested from the aqueous phase. Later on, MCs were allowed to stand for $4 \mathrm{~h}\left(4^{\circ} \mathrm{C}\right)$ for hardening and then recovered by centrifugation $\left(800 \mathrm{~g} \times 10 \mathrm{~min}\right.$ at $\left.4^{\circ} \mathrm{C}\right)$. Finally, samples were rinsed and resuspended in sterilized distilled water ( $\mathrm{pH} 7.0)$. These suspensions were used to characterize the MCs obtained (morphology, size and load).

In order to obtain empty MCs (negative control), the microencapsulation procedure was also carried out using saline solution instead of concentrated bacterial suspension.

\section{Enumeration of microencapsulated LAB}

To determine the viability of encapsulated Lactobacillus strains, MCs were dispersed in phosphate buffer ( $\mathrm{pH}$ 6.8) and incubated at $37^{\circ} \mathrm{C}(1 \mathrm{~h})$ by stirring $(75 \mathrm{opm})$, in order to dissolve the alginate matrix.
From the delivered LAB suspension, serial dilutions were carried out with peptone solution, plated in MRS medium and incubated at $37^{\circ} \mathrm{C}(24-48 \mathrm{~h})$. Taking into account the processed volumes of MCs suspensions, the CFU were referred to the total volume obtained, thus the total viable bacteria were calculated in each control time during the process.

\section{Characterization of the polymeric systems obtained (LAB- MCs)}

Microparticles morphology: Optical microscopy: $20 \mu \mathrm{l}$ of loaded/ empty MCs suspensions were mixed with $20 \mu \mathrm{l}$ methylene blue solution $(0.01 \% \mathrm{w} / \mathrm{v})$ and observed under an inverted microscope (Olympus CKX41).

Scanning Electron Microscopy (SEM): MCs obtained under the above experimental conditions were harvested and suspended in neutralized distilled water. Then, $500 \mu \mathrm{l}$ samples were incubated $1 \mathrm{~h}$ at $-70^{\circ} \mathrm{C}$ and freeze-dried at a condenser temperature of $-50^{\circ} \mathrm{C}$ at 110 militorr chamber pressure (Heto-FD4 freeze-dryer, Heto-Holten, Denmark) for $18 \mathrm{~h}$. MCs (as dried powder) were mounted, coated with gold and examined by SEM.

Microparticles load: The enumeration of viable bacteria included in the MCs or in the concentrated suspensions was performed through 10-times serial dilutions as described above (Micro particles morphology section). The load of viable cells was calculated taking into account the weight of the dried MCs contained in equal volume of suspension and was expressed as log CFU/g.

Resistance of microencapsulated LAB to freeze-drying process: MCs were suspended in both neutral distilled water and $6 \%$ skim milk. Then, $500 \mu \mathrm{l}$ samples were lyophilized as indicated above (Micro particles morphology section). In order to evaluate the cell-resistance to the lyophilization process, a survival factor $\left(\mathrm{SF}_{\mathrm{L}}\right)$ was defined according to the following equation:

$$
\mathrm{SF}_{\mathrm{L}}=1-\frac{\left[\log \left(\mathrm{CFU}_{\text {total }}\right)_{\text {Pre }}-\log \left(\mathrm{CFU}_{\text {total }}\right)_{\text {Post }}\right]}{\log \left(\mathrm{CFU} U_{\text {total }}\right)_{\text {Pre }}}
$$

$\log \left(\mathrm{CFU}_{\text {total }}\right)_{0}:$ microencapsulated lactic acid bacteria (LAB-MCs) viability before lyophilization

$\log \left(\mathrm{CFU}_{\text {total }}\right)_{\mathrm{f}}: \mathrm{LAB}-\mathrm{MCs}$ viability after lyophilization

$\mathrm{SF}_{\mathrm{L}}<1$ indicates low bacterial resistance to freeze-drying.

Survival of lyophilized microencapsulated LAB during storage: Dried LAB-MCs were fractionated in gelatin capsules and stored at $4^{\circ} \mathrm{C}$ for 60 and 90 days packed in plastic bottles with silica gel. LAB viability was determined after release from MCs as indicated previously (Enumeration of microencapsulated LAB section).

The cell viability during storage was expressed as survival factor during $\mathrm{t}$ months of storage (SFs), which was calculated as follows:

$$
\mathrm{SFs}=1-\frac{\left[\log (\mathrm{CFU} / \mathrm{ml})_{0}-\log (\mathrm{CFU} / \mathrm{ml})_{\mathrm{t}}\right]}{\log (\mathrm{CFU} / \mathrm{ml})_{0}}
$$

$\log (\mathrm{CFU} / \mathrm{ml})_{0}$ : LAB-MCs viability after lyophilization

$\log (\mathrm{CFU} / \mathrm{ml})_{\mathrm{t}}: \mathrm{LAB}-\mathrm{MCs}$ viability after storage at 60 and 90 days.

$\mathrm{SFs}<1$ indicates low bacterial resistance to storage. 
Citation: Ale CE, Torres Luque A, Gonzalez Moreno C, Otero MC (2015) Microencapsulation of Bovine Vaginal Lactobacilli in Alginate Using Emulsion-gelation: Freeze-drying, Storage and Antimicrobial Activity. J Bioprocess Biotech 5: 262. doi:10.4172/2155-9821.1000262

Page 3 of 8

Antimicrobial activity of microencapsulated and lyophilized $L$. gasseri CRL 1412: Co-culture assays were carried out in LAPTg broth $\mathrm{pH} 6.8$ for $12 \mathrm{~h}$ at $37^{\circ} \mathrm{C}$ under static conditions. L. gasseri CRL 1412 MCs were previously dissolved by using $2.5 \mathrm{ml} \mathrm{PBS} \mathrm{pH} 6,8\left(1 \mathrm{~h}, 37^{\circ} \mathrm{C}\right.$, $75 \mathrm{opm})$. The strains were inoculated to obtain $10^{8} \mathrm{CFU} / \mathrm{ml}$ of the $\mathrm{LAB}$ strain and $10^{3}-10^{4} \mathrm{CFU} / \mathrm{ml}$ of $E$. coli $99 / 14$. Bacterial growth was quantified by the plate dilution method using selective culture media: MacConkey agar for E. coli and MRS agar [21] pH 5.5 for the LAB strain. E. coli pure cultures were performed in LAPTg broth at $37^{\circ} \mathrm{C}$ under the same conditions. Moreover, associative cultures with empty MCs were carried out (as negative control).

\section{Process evaluation}

LAB viability evaluations during the whole process (initial cultures, concentrated suspensions, MCs suspensions) were performed and data were used to calculate the encapsulating factor and to determine both microencapsulation yield and efficiency.

The encapsulating factor (EF) was calculated using the following equation:

$$
E F=1-\frac{\left[\log \left(\mathrm{CFU}_{\text {total }}\right)_{0}-\log \left(\mathrm{CFU}_{\text {total }}\right)_{\mathrm{f}}\right]}{\log \left(\mathrm{CFU}_{\text {total }}\right)_{0}}
$$

$\log \left(\mathrm{CFU}_{\text {total }}\right)_{0}:$ LAB viability in bacterial concentrated suspensions.

$\log \left(\mathrm{CFU}_{\text {total }}\right)_{\mathrm{f}}:$ LAB viability in the MCs suspensions.

The microencapsulation yield $(\mathrm{Y})$ indicates the percentage represented by the MCs obtained with respect to the total weight of the material (alginate $+\mathrm{LAB}$ ). The yield was calculated according to the following expression:

$$
\mathrm{Y}(\%)=\frac{\text { weight of LAB }- \text { MCs obtained }(\mathrm{g})}{[\text { alginate weight }(\mathrm{g})+\text { LAB weight }(\mathrm{g})]} \times 100
$$

The LAB weight was determined considering an equivalent amount (concentrated suspension) of freeze-dried bacteria in sterilized distilled water, while the weight of the LAB-MCs obtained was calculated as the weight of the lyophilized LAB-MCs in sterilized distilled water.

With respect to microencapsulation efficiency (EE), it was calculated taken into account the relationship between the LAB-MCs and the theoretical available amount for encapsulation according to the following expression:

$$
\mathrm{EE}(\%)=\frac{\mathrm{LAB}-\mathrm{MCs}(\mathrm{CFU})}{\text { Theoretical available LAB }(\mathrm{CFU})} \times 100
$$

\section{Statistical analysis}

All the experiments were performed in duplicate. The cell viability data were logarithmically transformed, and then a statistical analysis by ANOVA-general linear model for residues analysis, determination of the effect of variables (strain, drying medium, storage time) and interactions on the cell viability (expressed by the different factors) were calculated for encapsulation, freeze-drying and storage processes. Also, significant differences between the mean values of each treatment were determined by using the LSD Fisher test ( $95 \%$ confidence interval). Data processing was carried out by MINITAB (version 14) and InfoStat (2015p Version) software.

\section{Results and Discussion}

Microencapsulation was proposed as a method to protect and ensure drug's delivery in specific tracts [19]. Nowadays, microencapsulation and freeze drying represent appropriate strategies to maintain the viability and stability of probiotics for use in both food and pharmaceutical technologies [24,25].

The microcapsules help fragile and sensitive materials to survive processing and packaging conditions and stabilize the shelf life of the active ingredient [26]. Also, the mucoadhesive properties of selected polymers promote intimate contact between the pharmaceutical form and the vaginal tissue and prolong the residence-time at the administration site [19]. Therefore, in this work the microencapsulation of bovine vaginal probiotics in alginate-MCs was studied.

\section{Morphology and bacterial load of the microcapsules (MCs)}

The MCs obtained were visualized as spheroidal particles (12$48 \mu \mathrm{m}$ ) with a fully charge of LAB (Figure 1a). Furthermore, the microstructure of the MCs obtained with the four LAB strains was analyzed by scanning electron microscopy and bacteria were observed on the surface as within in the polymeric matrix as shown for $L$. gasseri CRL 1412 (Figure $1 \mathrm{~b}$ and 1c) and L. delbrueckii subsp. delbrueckii CRL 1461 (Figure 1d). High magnification illustrated the interaction between encapsulated LAB and the alginate matrix (Figure $1 \mathrm{c}$ and $1 \mathrm{~d}$ ).

Regarding the MCs bacterial load, the analysis of variance indicated that the total load of LAB (log CFU/g) depended on the LAB strain and significant differences were observed between them $\left(\mathrm{R}^{2}=0.91, P<0.05\right)$ (Figure 2). MCs with L. gasseri CRL 1460 showed load of $8.98 \pm 0.15$ $\log \mathrm{CFU} / \mathrm{g}$, which was significantly higher (Fisher test, $P<0.05$ ) than those observed in L. gasseri CRL 1412-MCs $(8.19 \pm 0.17)$ and L. gasseri 1421 -MCs $(8.06 \pm 0.21 \log$ CFU/g). On the other hand, the mean load in the L. delbrueckii subsp. delbrueckii CRL 1461-MCs was $8.55 \pm 0.03$ $\log \mathrm{CFU} / \mathrm{g}$ (Figure 2) and did not show significant differences with $L$. gasseri CRL 1412 and CRL 1460.

Optical and scanning electron microscopies were proposed as analytical methods to characterize morphology and size of obtained particles [26]. They allowed us to observe spherical systems similar to another study [27] which reported the production of microcapsules of 10 to $40 \mu \mathrm{m}$ containing $L$. acidophilus in poly-lactic-co-glycolic acid matrix by using the emulsion-extraction technique. Also, a review [28] described the last microencapsulation techniques for probiotics and

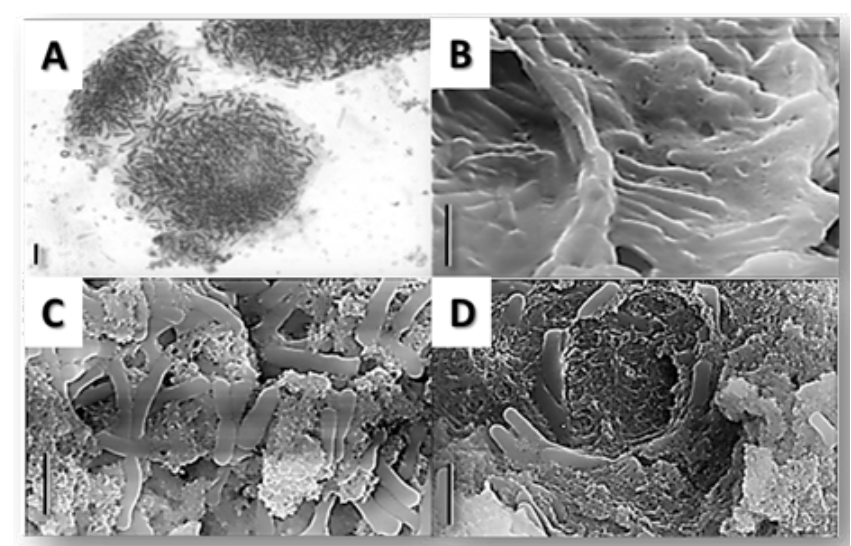

Figure 1: Morphology of alginate microcapsules containing bovine $L A B$ strains Optical microscopy: A: L. gasseri CRL 1412-MCs (Scale bar: $5 \mu \mathrm{m}$ ). Scanning electron microscopy: B: L. gasseri 1421-MCs; C: L. gasseri CRL 1412-MCs; D: L. delbruekii subsp. delbruekii CRL 1461-MCs (Scale bar: $1 \mu \mathrm{m}$ ). 


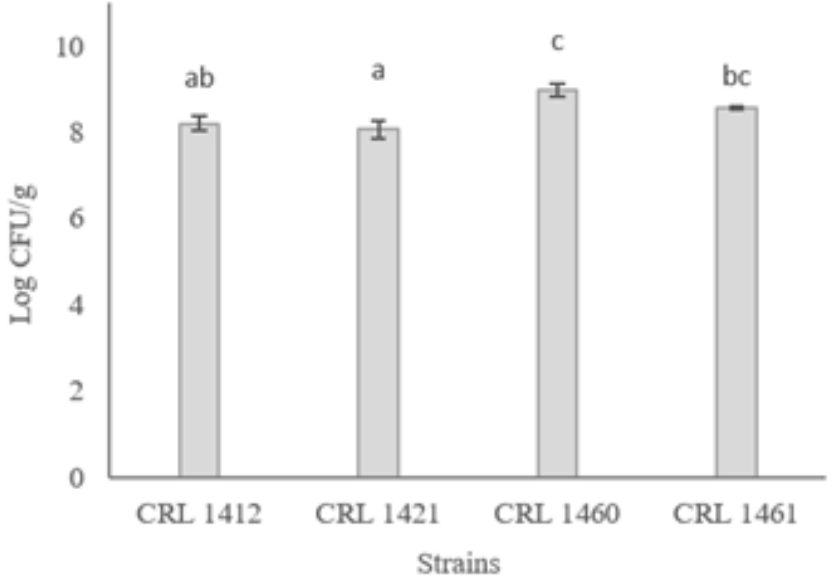

Figure 2: Final load in microcapsules for each $L A B$ strains. Means with a common letter are not significantly different (Fisher's test, $P<0.05$ ) for $L$. gasser CRL 1412, CRL 1421, CRL 1460 and L. delbruekii subsp. delbruekii CRL 1461.

pointed out the different bead materials and capsule sizes. The average size obtained with $3 \%$ alginate ranged $25 \mu \mathrm{m}$ to $1.17 \mathrm{~mm}$ in many reports.

Taking into account that cells from fresh cultures survive better than from lyophilized cultures during encapsulation by using the emulsion technique [28], in this work fresh culture of LAB strains instead of lyophilized ones were used for the microencapsulation process and the obtained systems were then freeze-dried. Also, the MCs load was strain-dependent as previously reported for microencapsulated probiotic lactobacilli for meat products [29].

\section{Freeze drying of microencapsulated LAB}

The resistance of LAB-MCs to freeze drying was expressed by a survival factor to lyophilization $\left(\mathrm{SF}_{\mathrm{L}}\right)$; and it was evaluated applying a full two-factor ANOVA test including 2 freeze-drying matrixes [Skim Milk (SM) and Neutral Sterilized Distilled Water (NDW)] and 4 LAB strains. Results indicated that all the observed variability could be explained by the selected model in which both considered factors (strain and matrix) and their interaction had a significant effect on $\mathrm{SF}_{\mathrm{L}}$ $\left(\mathrm{R}^{2}=0.96, P \leq 0.0001\right)$ (Table 1).

Overall, the mean $\mathrm{SF}_{\mathrm{L}}$ values ranged between $0.40 \pm 0.03$ and $0.84 \pm 0.03$ (Table 2). Regarding the behavior of each strain, multiple comparisons were performed; thus, L. delbrueckii subsp. delbrueckii CRL 1461 resulted to be the encapsulated LAB most resistant to the freeze drying process (Table 2). A previous report has indicated that this strain was sensitive to freeze-drying [30], thus, microencapsulation using alginate represents an option to keep cell viability and then to exert the beneficial effect. Other results have shown that alginate offers better protection for probiotic L. acidophilus and Bifidobacterium infantis than whey protein during freeze drying [28].

On the other hand, when suspension matrix was only considered, SM offered a significant protection to the lyophilization process compared with $\mathrm{SF}_{\mathrm{L}}$ values obtained in $\mathrm{NDW}$ (general mean $\mathrm{SF}_{\mathrm{L}}=0.82$ \pm 0.05 and $0.51 \pm 0.05$, respectively). Although, SM significantly improved resistance to freeze-drying process (Table 3), L. gasseri CRL 1412 showed similar mean $\mathrm{SF}_{\mathrm{L}}$ values in both matrix $(0.70 \pm 0.05$ and $0.72 \pm 0.05$ in NDW and SM, respectively) (Table 3). It is interesting to point out that L. gasseri CRL 1412 viability loss was significantly higher in water than skim milk during lyophilization of free cells of this strain [30]. Thus, the alginate microencapsulation improved the LAB strain resistance when freeze-dried in water.

\section{Viability of freeze dried-encapsulated LAB during storage}

The degree of survival of freeze-dried encapsulated LAB in SM and NDW was determined during the storage at $4^{\circ} \mathrm{C}$ and therefore a survival factor to storage $\left(\mathrm{SF}_{\mathrm{S}}\right)$ was defined. To evaluate $\mathrm{SF}_{\mathrm{S}}$ a full threefactor ANOVA test was applied including strain, suspension matrix (SM and NDW), storage-time (60 and 90 days) and their interactions. This analysis explained satisfactorily the SFs variability observed for dried encapsulated LAB (Table 4). Moreover, the survival of the freezedried encapsulated-LAB during storage was significantly different for each strain and depended on the lyophilization matrix (significant interaction $S \times C, P<0.0001$ ) (Table 4) but was not affected by the storage time (interaction $\mathrm{S} \times \mathrm{T}, P=0.2453$ ).

Multiple comparisons between mean values obtained for each LAB strain were performed. Thus, L. gasseri CRL 1421 was significantly more resistant to storage (mean $\mathrm{SF}_{\mathrm{s}}=0.87 \pm 0.03$ ) than the other $\mathrm{LAB}$

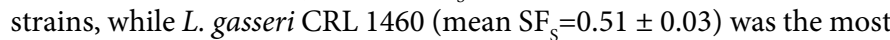
sensitive strain. However, CRL $1421 \mathrm{SF}_{\mathrm{S}}$ was comparable with those observed for CRL $1412\left(\right.$ mean $\left.\mathrm{SF}_{\mathrm{s}}=0.82 \pm 0.03\right)$ (Table 5). SM offered to encapsulated-LAB a significant higher protection during storage (mean $\mathrm{SF}_{\mathrm{s}}=1 \pm 0.02$ ) than NDW (mean $\mathrm{SF}_{\mathrm{s}}=0.48 \pm 0.02, P<0.05$ ). Moreover, there was no significant difference between 60 and 90 days of storage (mean $\mathrm{SF}_{\mathrm{S}}=0.77 \pm 0.02$ and $0.72 \pm 0.02$, respectively) (Table 5).

In order to evaluate the optimal condition for each LAB strain, $\mathrm{SF}_{\mathrm{S}}$ mean values were analyzed taking into account the matrix of lyophilization, storage-time and strain (Table 6). Multiple comparisons indicated that MCs containing L. gasseri CRL 1412 lyophilized in SM and stored during 60 days showed highest $\mathrm{SF}_{\mathrm{S}}$ (mean $\mathrm{SF}_{\mathrm{S}}=1.22 \pm 0.07$ ). However, this last value was comparable with those observed for microencapsulated L. gasseri CRL 1421 lyophilized in SM and storage during 60 and 90 days (mean $\mathrm{SF}_{\mathrm{s}}=1.07 \pm 0.07$ and $1.12 \pm 0.07$ for 60 and 90 days, respectively). However, no viability of $L$. gasseri CRL 1460 was recovered when lyophilized in NDW and stored for 60 days (Table 6).

The lowest $\mathrm{SF}_{\mathrm{S}}$ values were detected when $\mathrm{LAB}$ strains were lyophilized in NDW, however $L$. delbrueckii subsp. delbrueckii CRL 1461 stored during 90 days showed similar values (mean $\mathrm{SF}_{\mathrm{s}}=0.66 \pm$ $0.07)$ when lyophilized in SM and was significantly lower $(P<0.05)$ with respect to the other $\mathrm{SF}_{\mathrm{S}}$ for SM (Table 6).

It was reported that encapsulation of LAB in alginate improves its survival rates when compared to free cell counts stored in SM during $24 \mathrm{~h}$. The survival to storage of Lactobacillus bulgaricus in this matrix was even higher when the LAB strain was encapsulated with alginate and chitosan [28]. Moreover, it has been demonstrated that low viability of vaginal $L$. reuteri CRL 1324 was recovered after xanthangellan encapsulation and lyophilization in SM [25]. However, when this LAB strain was freeze-dried in $\mathrm{SM}+$ lactose, a higher viability was obtained during up to 60 days storage at $4^{\circ} \mathrm{C}$ [25]. In our study, a high viable $\mathrm{LAB}$ count included in alginate MCs was obtained without the addition of lactose.

Despite the extra costs, microencapsulation has profit-making potential in markets of high value products or products (microorganisms or drugs) where microencapsulation is absolutely necessary. Therefore, our finding represents an alternative to diminish the production costs. 
Citation: Ale CE, Torres Luque A, Gonzalez Moreno C, Otero MC (2015) Microencapsulation of Bovine Vaginal Lactobacilli in Alginate Using Emulsion-gelation: Freeze-drying, Storage and Antimicrobial Activity. J Bioprocess Biotech 5: 262. doi:10.4172/2155-9821.1000262

Page 5 of 8

\section{Antimicrobial efficacy of LAB-MCs}

Viability of E. coli $99 / 14$ was studied at 2 and 12 h of incubation in co-cultures with MCs loaded with L. gasseri CRL 1412; cocultures with empty-MCs and pure cultures were used as controls. The ANOVA analysis $\left(\mathrm{R}^{2}=0.96\right)$ indicated that the pathogen viability showed variations with time, and it was culture-dependent (significant interaction $\mathrm{T} \times \mathrm{C}, P<0.0001$ ) (Table 7). During the first $2 \mathrm{~h}$ no significant differences were found for any culture $(P \leq 0.05$, Fisher's

\begin{tabular}{|c|c|c|c|c|}
\hline Source of variation & SS $^{*}$ & DF $^{*}$ & MS $^{\mathbf{*}}$ & F-stat $^{+}$ \\
\hline Model & 1.14 & 7 & 0.16 & $41.39^{*}$ \\
\hline Strain (S) & 0.41 & 3 & 0.14 & $35.14^{*}$ \\
\hline Condition (C) & 0.37 & 1 & 0.37 & $93.62^{*}$ \\
\hline S $\times C^{* * *}$ & 0.36 & 3 & 0.12 & $30.22^{*}$ \\
\hline Residuals & 0.03 & 8 & $3.9 \times 10^{-3}$ & \\
\hline Total & 1.17 & 15 & & \\
\hline
\end{tabular}

${ }^{*} P<0.0001$. ${ }^{*}$ Sum of squares, ${ }^{\# D e g r e e s ~ o f ~ f r e e d o m, ~ \& ~ M e a n ~ s q u a r e s, ~}{ }^{+} \mathrm{F}$-Statistical. "Lyophilization matrix (NDW or SM). ${ }^{* * *}$ Represents interaction.

Table 1: ANOVA for survival factor to lyophilization $\left(S_{L}\right)$ of microencapsulated LAB.

\begin{tabular}{|c|c|c|c|c|c|}
\hline Strain & SF $_{\text {L mean }}$ & $\mathbf{n}$ & & & \\
\hline L gasseri CRL 1460 & $0.4 \pm 0.03$ & 4 & $\mathrm{~A}^{*}$ & & \\
\hline L gasseri CRL 1412 & $0.71 \pm 0.03$ & 4 & & $\mathrm{~B}$ & \\
\hline L gasseri CRL 1421 & $0.71 \pm 0.03$ & 4 & & $\mathrm{~B}$ & \\
\hline L. delbrueckii subsp. delbrueckii CRL 1461 & $0.84 \pm 0.03$ & 4 & & & $\mathrm{C}$ \\
\hline
\end{tabular}

"Means with a common letter are not significantly different (Fisher's test, $P<0.05$ ).

Table 2: Survival factor to lyophilization $\left(\mathrm{SF}_{L}\right)$ for each microencapsulated $L A B$ strain.

\begin{tabular}{|c|c|c|c|c|c|c|c|}
\hline Strain & Condition $^{* *}$ & Mean & n & & & & \\
\hline L. gasseri CRL 1460 & NDW & $0 \pm 0.04$ & 2 & A $^{*}$ & & & \\
\hline L. gasseri CRL 1421 & NDW & $0.61 \pm 0.04$ & 2 & & B & & \\
\hline L. gasseri CRL 1412 & NDW & $0.7 \pm 0.04$ & 2 & & B & C & \\
\hline $\begin{array}{c}\text { L. gasseri CRL 1412 } \\
\text { L. delbrueckii subsp. delbrueckii } \\
\text { CRL 1461 }\end{array}$ & NDW & $0.72 \pm 0.04$ & 2 & & B & C & \\
\hline $\begin{array}{c}\text { L. gasseri CRL 1460 } \\
\text { L. gasseri CRL 1421 }\end{array}$ & SM & $0.76 \pm 0.04$ & 2 & & & C & \\
\hline $\begin{array}{c}\text { L. delbrueckii subsp. delbrueckii } \\
\text { CRL 1461 }\end{array}$ & SM & $0.82 \pm 0.04$ & 2 & & & C & D \\
\hline
\end{tabular}

"Means with a common letter are not significantly different (Fisher's test, $P<0.05$ ). "Lyophilization matrix: SM: Skim Milk, NDW: Neutral Sterilized Distilled Water.

Table 3: Survival factor to lyophilization $\left(S_{L}\right)$ for microencapsulated $L A B s$ in different conditions.

\begin{tabular}{|c|c|c|c|c|}
\hline Source of variation & SS ${ }^{*}$ & DF $^{\#}$ & MS $^{\&}$ & F-stat ${ }^{+}$ \\
\hline Model & 3.86 & 15 & 0.26 & $29.79^{*}$ \\
\hline Strain (S) & 0.64 & 3 & 0.21 & $24.78^{*}$ \\
\hline Condition $(C)^{* *}$ & 2.13 & 1 & 2.13 & $246.43^{\circ}$ \\
\hline Time $(\mathrm{T})$ & 0.02 & 1 & 0.02 & 2.26 \\
\hline$S \times C^{* * *}$ & 0.97 & 3 & 0.32 & $37.46^{*}$ \\
\hline$S \times T^{* * *}$ & 0.04 & 3 & 0.01 & 1.53 \\
\hline $\mathrm{C} \times \mathrm{T}^{* * *}$ & 0.02 & 1 & 0.02 & 2.26 \\
\hline $\mathrm{S} \times \mathrm{C} \times \mathrm{T}^{*+1}$ & 0.04 & 3 & 0.01 & 1.53 \\
\hline Residuals & 0.14 & 16 & 0.01 & \\
\hline Total & 4 & 31 & & \\
\hline
\end{tabular}

${ }^{*} P<0.0001$. ${ }^{*}$ Sum of squares, \#Degrees of freedom, \&Mean squares, ${ }^{+}$F-Statistical)." Lyophilization matrix: SM: Skim Milk, NDW: Neutral Sterilized Distilled Water." Represents interaction.

Table 4: ANOVA for storage survival factor (SFs) of freeze-dried microencapsulated LAB.

\begin{tabular}{|c|c|c|c|c|c|}
\hline Strain & Mean & n & & & \\
\hline L. gasseri CRL 1421 & $0.87 \pm 0.03$ & 8 & $\mathrm{~A}^{*}$ & & \\
\hline L. gasseri CRL 1412 & $0.82 \pm 0.03$ & 8 & $\mathrm{~A}$ & $\mathrm{~B}$ & \\
\hline $\begin{array}{c}\text { L. delbrueckii subsp. delbrueckii CRL } \\
\text { 1461 }\end{array}$ & $0.77 \pm 0.03$ & 8 & & $\mathrm{~B}$ & \\
\hline L. gasseri CRL 1460 & $0.51 \pm 0.03$ & 8 & & & $\mathrm{C}$ \\
\hline Drying condition" & & & & & \\
\hline SM & $1 \pm 0.02$ & 16 & $\mathrm{~A}$ & & \\
\hline NDW & $0.48 \pm 0.02$ & 16 & & $\mathrm{~B}$ & \\
\hline Storage time (days) & & & & & \\
\hline 60 & $0.77 \pm 0.02$ & 16 & $\mathrm{~A}$ & & \\
\hline 90 & $0.72 \pm 0.02$ & 16 & $\mathrm{~A}$ & & \\
\hline
\end{tabular}

"Means with a common letter are not significantly different (Fisher's test, $P<0.05$ ). "Lyophilization matrix: SM: Skim Milk, NDW: Neutral Sterilized Distilled Water.

Table 5: Storage survival factor (SFs) for freeze-dried microencapsulated LAB strains.

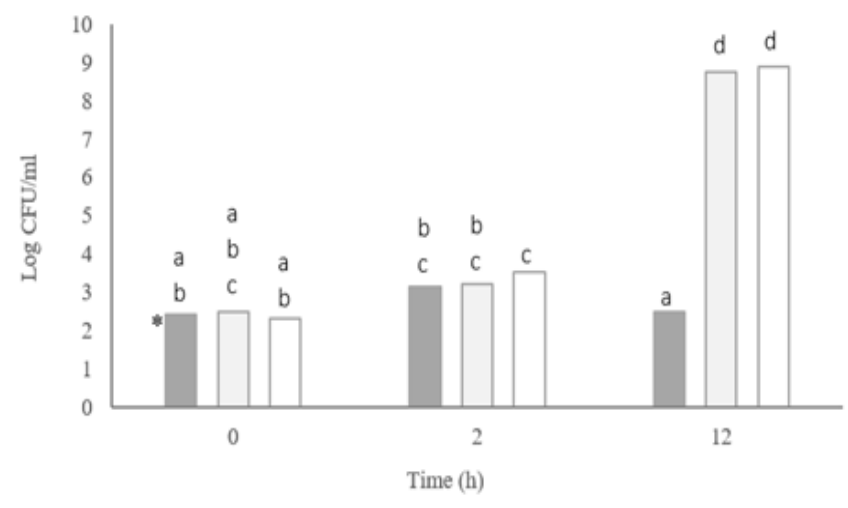

$\square$ E. coli + CRL 1412-MCs $\square$ E. coli + empty MCs $\quad \square$ Pure culture $E$. coli $99 / 14$

Figure 3: E. coli 99/14 viability in mixed cultures. $\left(^{*}\right)$ Bars represent the concentration of cells of $E$. coli 99/14 in co-cultures (E. coli + CRL 1412-MCs) and control cultures (E. coli + empty MCs and $E$. coli in pure culture). Means with a common letter are not significantly different (Fisher's test, $P<0.05$ ).

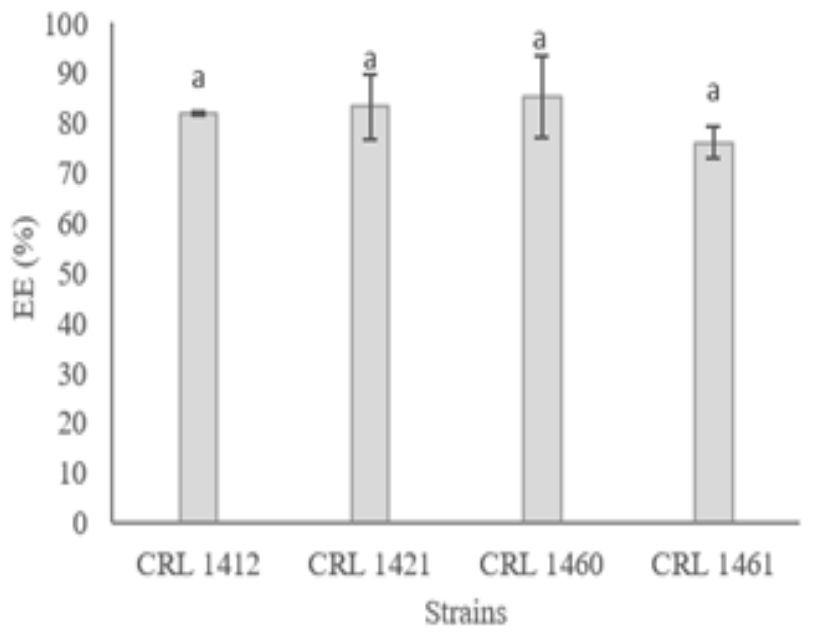

Figure 4: Efficiency of encapsulation process calculated for $L$. gasseri CRL 1412, CRL 1421, CRL 1460 and L. delbruekii subsp. delbruekii CRL 1461. Means with a common letter are not significantly different (Fisher's test, $P<0.05)$. 
Citation: Ale CE, Torres Luque A, Gonzalez Moreno C, Otero MC (2015) Microencapsulation of Bovine Vaginal Lactobacilli in Alginate Using Emulsion-gelation: Freeze-drying, Storage and Antimicrobial Activity. J Bioprocess Biotech 5: 262. doi:10.4172/2155-9821.1000262

Page 6 of 8

\begin{tabular}{|c|c|c|c|c|c|c|c|c|c|c|c|}
\hline Strain & Condition ${ }^{*}$ & Time $^{\#}$ & Mean & $\mathbf{n}$ & & & & & & & \\
\hline L. gasseri CRL 1412 & SM & 60 & $1.22 \pm 0.07$ & 2 & $A^{*}$ & & & & & & \\
\hline L. gasseri CRL 1421 & SM & 90 & $1.12 \pm 0.07$ & 2 & $A$ & B & & & & & \\
\hline L. gasseri CRL 1421 & SM & 60 & $1.07 \pm 0.07$ & 2 & $A$ & B & $\mathrm{C}$ & & & & \\
\hline L. gasseri CRL 1460 & SM & 90 & $1.03 \pm 0.07$ & 2 & $A$ & B & $\mathrm{C}$ & & & & \\
\hline L. gasseri CRL 1412 & SM & 90 & $1 \pm 0.07$ & 2 & & B & $\mathrm{C}$ & & & & \\
\hline L. gasseri CRL 1460 & SM & 60 & $1 \pm 0.07$ & 2 & & B & $\mathrm{C}$ & & & & \\
\hline $\begin{array}{l}\text { L. delbrueckii subsp. delbrueckii CRL } \\
\qquad 1461\end{array}$ & SM & 60 & $0.91 \pm 0.07$ & 2 & & & $\mathrm{C}$ & $\mathrm{D}$ & & & \\
\hline $\begin{array}{l}\text { L. delbrueckii subsp. delbrueckii CRL } \\
\qquad 1461\end{array}$ & NDW & 60 & $0.75 \pm 0.07$ & 2 & & & & $\mathrm{D}$ & $E$ & & \\
\hline $\begin{array}{l}\text { L. delbrueckii subsp. delbrueckii CRL } \\
\qquad 1461\end{array}$ & NDW & 90 & $0.75 \pm 0.07$ & 2 & & & & $\mathrm{D}$ & $E$ & & \\
\hline $\begin{array}{l}\text { L. delbrueckii subsp. delbrueckii CRL } \\
\qquad 1461\end{array}$ & SM & 90 & $0.66 \pm 0.07$ & 2 & & & & & $E$ & $\mathrm{~F}$ & \\
\hline L. gasseri CRL 1421 & NDW & 60 & $0.65 \pm 0.07$ & 2 & & & & & $E$ & $\mathrm{~F}$ & \\
\hline L. gasseri CRL 1421 & NDW & 90 & $0.65 \pm 0.07$ & 2 & & & & & $E$ & $\mathrm{~F}$ & \\
\hline L. gasseri CRL 1412 & NDW & 60 & $0.53 \pm 0.07$ & 2 & & & & & & $\mathrm{~F}$ & \\
\hline L. gasseri CRL 1412 & NDW & 90 & $0.53 \pm 0.07$ & 2 & & & & & & $\mathrm{~F}$ & \\
\hline L. gasseri CRL 1460 & NDW & 90 & 0 & 2 & & & & & & & G \\
\hline L. gasseri CRL 1460 & NDW & 60 & 0 & 2 & & & & & & & G \\
\hline
\end{tabular}

"Means with a common letter are not significantly different (Fisher's test, $\mathrm{P}<0.05)$.

*Lyophilization matrix; SM: Skim Milk; NDW: Neutral Sterilized Distilled Water

Table 6: Stored survival factor (SFs) for freeze-dried microencapsulated LAB strains in different conditions.

\begin{tabular}{|c|c|c|c|}
\hline Source of variation & SS $^{*}$ & DF $^{*}$ & F- $^{\text {stat }}{ }^{+}$ \\
\hline Model & 179.83 & 8 & $48.90^{\star}$ \\
\hline Time $(\mathrm{T})^{\star *}$ & 85.03 & 2 & $92.48^{\star}$ \\
\hline Culture $(\mathrm{C})^{* *+}$ & 33.41 & 2 & $36.34^{\star}$ \\
\hline $\mathrm{T} \times \mathrm{C}^{\star \#}$ & 61.38 & 4 & $33.38^{\star}$ \\
\hline Residuals & 8.27 & 18 & \\
\hline Total & $\mathbf{1 8 8 . 1 0}$ & $\mathbf{2 6}$ & \\
\hline
\end{tabular}

that alginate did not have antagonistic effect on the pathogen's viability. Thus, these studies allow us to advance in the formulation of probiotics for metritis control.

\section{Evaluation of the encapsulation process}

In order to evaluate the encapsulation process independently from the initial bacterial number, an Encapsulation Factor (EF) was defined. The EF values obtained for the four LAB strains ranged between 0.76 \pm 0.03 and $0.85 \pm 0.08$ and there were no significant differences among them $(P<0.05)$.

Overall, a loss of LAB viability was observed during the different * 99/14 with CRL 1412-MCs, co-culture of E. coli 99/14 with empty MCs and pure cultures of $E$. coli 99/14. "*Represents interaction

Table 7: ANOVA $\left(n=27, R^{2}=0.96\right)$ of $E$. coli $99 / 14$ viability co-cultured with MCs containing L. gasseri CRL 1412.

test). However, after $12 \mathrm{~h}$ of incubation, a significant reduction in $E$. coli 99/14 viability was detected when co-cultured with filled capsules. The pathogen viability in the pure culture and co-cultured with both empty and filled capsules was $8.73 \pm 0.39,8.88 \pm 0.39$ and $1.93 \pm 0.39$ $\mathrm{CFU} / \mathrm{ml}$, respectively (Figure 3 ). On the other hand, it was determined that the growth of the pathogen in cultures with empty-capsules was comparable with the viability observed for its pure culture during the assay $(12 \mathrm{~h})(P \leq 0.05)$.

The capability of indigenous $\mathrm{LAB}$ strains to remain viable and functionally active during long-term storage is an important requirement for beneficial micro-organisms [31]. Escherichia coli have been reported as a crucial agent responsible for metritis and reproductive disturbances in cows $[32,33]$. Taken into consideration the inhibitory activity of cell-free supernatants from L. gasseri CRL 1412 against E. coli 99/14 [19] the effect of lyophilized L. gasseri CRL $1412-M C s$ against the pathogenic bacterium reported in this work, represents the first study of LAB-MCs co-cultured with E. coli. Also, co-cultures with empty MCs were performed and the results indicate stages of the encapsulation process (data not shown). This diminution could be attributed to handling of LAB cells (harvesting, concentration, cultures transfer) and to the encapsulation process. Nevertheless, nonsignificant differences were observed between EF values for each strain. This factor constitutes a useful tool to evaluate a process regardless of the initial cell number. It has been previously proposed to evaluate other processes (lyophilization) that involve LAB/yeasts viable cells $[30,33,34]$.

The encapsulating process efficiency (EE\%) was calculated to compare the obtained amount of viable LAB included in the MCs in relation to the theoretical values. The $\mathrm{EE} \%$ values ranged between $76.07 \pm 3.22$ and $85.12 \pm 8.17$ (Figure 4) without significant differences between LAB-strains $(P<0.05$, Fisher's test $)$ with a mean value of $75 \%$. These results are in agreement with a previous study [35] which reported an $\mathrm{EE}=74 \%$ when Lactobacillus fermentum was encapsulated in $3 \%$ alginate by the emulsion-ionic gelation technique. However, a previous study [18] reported an $\mathrm{EE}=36-38 \%$ for $L$. acidophilus encapsulated in $3 \%$ alginate by the same technique.

The microencapsulation yield $(\mathrm{Y})$ is an important control from the economic point of view in any encapsulation process, considering the cost of polymers and active principles used. Therefore it is desirable 
Citation: Ale CE, Torres Luque A, Gonzalez Moreno C, Otero MC (2015) Microencapsulation of Bovine Vaginal Lactobacilli in Alginate Using Emulsion-gelation: Freeze-drying, Storage and Antimicrobial Activity. J Bioprocess Biotech 5: 262. doi:10.4172/2155-9821.1000262

Page 7 of 8

to recover most of the starting material as MCs [36]. In our work conditions, the mean value of $\mathrm{Y}$ was $50.5 \%$ for all the LAB strains. This value was similar to another report [37] that used the coacervation and phase separation techniques for the preparation of microspheres loaded with Bacillus coagulans ; it was also reported for Lactobacillus rhamnosus by using the extrusion technique with $4 \%$ alginate $+2 \%$ chitosan [38,39].

\section{Conclusion}

In conclusion, the microencapsulation of bovine potentially probiotic $\mathrm{LAB}$ in $3 \%$ alginate by using the emulsion-gelation technique, freeze-drying process in skim milk and storage at $4^{\circ} \mathrm{C}$ for 90 days, kept the $\mathrm{LAB}$ viability and capability to inhibit $E$. coli, which represents one of the main pathogens associated with bovine metritis. Therefore, these bio-adhesive systems can be included in the design of a veterinarian product to be locally applied to restore the vaginal microbiota; in order to prevent infections in the BRT in a sustainable way. Further studies must be performed to evaluate the survival and colonization of the microencapsulated LAB in the bovine vagina.

\section{Acknowledgements}

This research was supported by grants from Consejo Nacional de Investigaciones Científicas y Técnicas (PIP 300).

\section{References}

1. LeBlanc SJ (2008) Postpartum uterine disease and dairy herd reproductive performance: a review. Vet J 176: 102-114.

2. Sheldon IM, Williams EJ, Miller AN, Nash DM, Herath S (2008) Uterine diseases in cattle after parturition. Vet J 176: 115-121.

3. Zhu YG, Johnson TA, Su JQ, Qiao M, Guo GX, et al. (2013) Diverse and abundant antibiotic resistance genes in Chinese swine farms. Proc Natl Acad Sci USA 110: 3435-3440.

4. Kritas SK, Morrison RB (2007) Effect of orally administered Lactobacillus case on porcine reproductive and respiratory syndrome (PRRS) virus vaccination in pigs. Vet Microbiol 119: 248-255.

5. Bai SP, Wu AM, Ding XM, Lei Y, Bai J, et al. (2013) Effects of probioticsupplemented diets on growth performance and intestinal immune characteristics of broiler chickens. Poult Sci 92: 663-670.

6. Bouchard DS, Rault L, Berkova N, Le Loir Y, Even S (2013) Inhibition of Staphylococcus aureus invasion into bovine mammary epithelial cells by contact with live Lactobacillus casei. Appl Environ Microbiol 79: 877-885.

7. Arqués JL, Rodríguez E, Langa S, Landete JM, Medina M (2015) Antimicrobia activity of lactic acid bacteria in dairy products and gut: effect on pathogens. Biomed Res Int 2015: 584183.

8. Wen K, Liu F, Li G, Bai M, Kocher J, et al. (2015) Lactobacillus rhamnosus GG Dosage Affects the Adjuvanticity and Protection Against Rotavirus Diarrhea in Gnotobiotic Pigs. J Pediatr Gastroenterol Nutr 60: 834-843.

9. Otero MC, Nader-Macías ME (2012) Probióticos para el ganado bovino Probióticos y salud. (Eds) Diaz-Santos, Madrid, Spain, 632-690.

10. Otero MC, Silva de Ruiz C, Ibáñez R, Wilde O, Ruiz Holgado A, et al. (1999) Lactobacilli and Enterococci isolated from the bovine vaginal during the estrous cycle. Anaerobe 5: 305-307.

11. Otero C, Saavedra L, Silva de Ruiz C, Wilde O, Holgado AR, et al. (2000) Vaginal bacterial microflora modifications during the growth of healthy cows. Lett Appl Microbiol 31: 251-254

12. Nishiyama K, Ueno S, Sugiyama M, Yamamoto Y, et al. (2015) Lactobacillus rhamnosus GG SpaC pilin subunit binds to the carbohydrate moieties of intestinal glycoconjugates. Anim Sci J.

13. Berner D, Viernstein $H$ (2006) Effect of protective agents on the viability of Lactococcus lactis subjected to freeze-thawing and freeze-drying. Sci Pharm 74: 137-149.
14. Anal AK, Singh H (2007) Recent advances in microencapsulation of probiotics for industrial applications and targeted delivery. Trends Food Sci Tech 18: 240251.

15. Champagne CP, Fustier $P$ (2007) Microencapsulation for the improved delivery of bioactive compounds into foods. Curr Opin Biotechnol 18: 184-190.

16. Albertini B, Vitali B, Passerini N, Cruciani F, Di Sabatino M, et al. (2010) Development of microparticulate systems for intestinal delivery of Lactobacillus acidophilus and Bifidobacterium lactis. Eur J Pharm Sci 40: 359-366.

17. Martín MJ, Lara-Villoslada F, Ruiz MA, Morales ME (2014) Microencapsulation of bacteria: A review of different technologies and their impact on the probiotic effects. Innov Food Sci Emerg 27: 15-25.

18. Cai S, Zhao M, Fang Y, Nishinari K, Phillips GO, et al. (2014) Microencapsulation of Lactobacillus acidophilus CGMCC1.2686 via emulsification/internal gelation of alginate using $\mathrm{Ca}-\mathrm{EDTA}$ and $\mathrm{CaCO}_{3}$ as calcium sources. Food Hydrocoll 39: 295-300.

19. Martín-Villena MJ, Fernández-Campos F, Calpena-Campmany AC, Bozal-de Febrer N, Ruiz-Martínez MA, et al. (2013) Novel microparticulate systems for the vaginal delivery of nystatin: development and characterization. Carbohydr Polym 94: 1-11.

20. Otero MC, Morelli L, Nader-Macías ME (2006) Probiotic properties of vagina lactic acid bacteria to prevent metritis in cattle. Lett Appl Microbiol 43: 91-97.

21. De Man JC, Rogosa M, Sharpe ME (1960) A medium for the cultivation of lactobacilli. J Appl Bacteriol 23: 130-135.

22. Raibaud P, Galpin JV, Ducluzeau R, Mocquot G, Oliver G (1973) The "Lactobacillus" genus in the digestive tract of rats. I. Characteristics of homofermentative strains isolated from holo- and gnotoxenic rats. Ann Microbiol (Paris) 124: 83-109.

23. Shah NP, Ravula RR (2000) Microencapsulation of probiotic bacteria and their survival in frozen fermented dairy desserts. Aust J Dairy Technol 55: 139-144.

24. Jiménez M, Flores-Andrade E, Pascual-Pineda LA, Beristain Cl (2015) Effect of water activity on the stability of Lactobacillus paracasei capsules. LWT - Food Sci Technol 60: 346-351.

25. Juárez Tomás MS, De Gregorio PR, Leccese Terraf MC, Nader-Macías ME (2015) Encapsulation and subsequent freeze-drying of Lactobacillus reuteri CRL 1324 for its potential inclusion in vaginal probiotic formulations. Eur $J$ Pharm Sci 79: 87-95.

26. Azagheswari BK, Padma S, Priya SP (2015) A Review on Microcapsules Global J Pharmacol 9: 28-39.

27. Della Porta G, Castaldo F, Scognamiglio M, Paciello L, Parascandola P, et al. (2012) Bacteria microencapsulation in PLGA microdevices by supercritical emulsion extraction. J Supercrit Fluids 63: 1-7.

28. Rokka S, Rantamäki P (2010) Protecting probiotic bacteria by microencapsulation: challenges for industrial applications. Eur Food Res Technol 231: 1-12.

29. Jähne J, Bonaparte C, Kühne M, Klein G (2013) Viability of microencapsulated probiotic lactobacilli during storage at different temperatures. Berl Munch Tierarztl Wochenschr 126: 10-15.

30. Otero MC, Espeche MC, Nader-Macías MEF (2007) Optimization of the freezedrying media and survival throughout storage of freeze-dried Lactobacillus gasseri and Lactobacillus delbrueckii subsp. delbrueckii for veterinarian probiotic applications. Process Biochem 42: 1406-1411.

31. Sanders ME, Klaenhammer TR (2001) Invited review: the scientific basis of Lactobacillus acidophilus NCFM functionality as a probiotic. J Dairy Sci 84 : 319-331.

32. Santos TM, Gilbert RO, Caixeta LS, Machado VS, Teixeira LM, et al. (2010) Susceptibility of Escherichia coli isolated from uteri of postpartum dairy cows to antibiotic and environmental bacteriophages. Part II: In vitro antimicrobial activity evaluation of a bacteriophage cocktail and several antibiotics. J Dairy Sci 93: 105-114. 
Citation: Ale CE, Torres Luque A, Gonzalez Moreno C, Otero MC (2015) Microencapsulation of Bovine Vaginal Lactobacilli in Alginate Using Emulsion-gelation: Freeze-drying, Storage and Antimicrobial Activity. J Bioprocess Biotech 5: 262. doi:10.4172/2155-9821.1000262

Page 8 of 8

33. Montel Mendoza G, Pasteris SE, Otero MC, Fatima Nader-Macías ME (2014) Survival and beneficial properties of lactic acid bacteria from raniculture subjected to freeze-drying and storage. J Appl Microbiol 116: 157-166.

34. Sheldon IM, Rycroft AN, Dogan B, Craven M, Bromfield JJ, et al. (2010) Specific strains of Escherichia coli are pathogenic for the endometrium of cattle and cause pelvic inflammatory disease in cattle and mice. PLoS One 5: e9192.

35. Ale CE, Otero MC, Pasteris S (2015) Freeze-drying of wine yeasts and Oenococcus oeni and selection of the inoculation conditions after storage. $J$ Bioprocess Biotech 5: 248.

36. Martin MJ, Lara Villoslada F, Ruiz MA, Morales ME (2013) Effect of unmodified starch on viability of alginate-encapsulated Lactobacillus fermentum CECT5716. LWT-Food Sci Technol 53: 480-486.
37. Vila J, Jose L (2001) Tecnología Farmacéutica Volumen I: Aspectos fundamentales de los sistemas farmacéuticos y operaciones básicas. España: Editorial Síntesis, SA.

38. Alli SM (2011) Formulation and evaluation of Bacillus coagulans-loaded hypromellose mucoadhesive microspheres. Int J Nanomedicine 6: 619-629.

39. Abbaszadeh S, Gandomi H, Misaghi A, Bokaei S, Noori N (2014) The effect of alginate and chitosan concentrations on some properties of chitosan-coated alginate beads and survivability of encapsulated Lactobacillus rhamnosus in simulated gastrointestinal conditions and during heat processing. J Sci Food Agric 94: 2210-2216. 